\title{
Radiative and Dynamical Influences on Polar Stratospheric Temperature Trends $\mathscr{A}$
}

\author{
DIANE J. IVY AND SUSAN SOLOMON \\ Department of Earth, Atmospheric and Planetary Sciences, Massachusetts Institute of Technology, \\ Cambridge, Massachusetts \\ HARALD E. RIEDER \\ Wegener Center for Climate and Global Change, and Institute for Geophysics, Astrophysics, and Meteorology/Department \\ of Physics, University of Graz, Graz, and Austrian Polar Research Institute, Vienna, Austria
}

(Manuscript received 21 July 2015, in final form 6 November 2015)

\begin{abstract}
Radiative and dynamical heating rates control stratospheric temperatures. In this study, radiative temperature trends due to ozone depletion and increasing well-mixed greenhouse gases from 1980 to 2000 in the polar stratosphere are directly evaluated, and the dynamical contributions to temperature trends are estimated as the residual between the observed and radiative trends. The radiative trends are obtained from a seasonally evolving fixed dynamical heating calculation with the Parallel Offline Radiative Transfer model using four different ozone datasets, which provide estimates of observed ozone changes. In the spring and summer seasons, ozone depletion leads to radiative cooling in the lower stratosphere in the Arctic and Antarctic. In Arctic summer there is weak wave driving, and the radiative cooling due to ozone depletion is the dominant driver of observed trends. In late winter and early spring, dynamics dominate the changes in Arctic temperatures. In austral spring and summer in the Antarctic, strong dynamical warming throughout the mid- to lower stratosphere acts to weaken the strong radiative cooling associated with the Antarctic ozone hole and is indicative of a strengthening of the Brewer-Dobson circulation. This dynamical warming is a significant term in the thermal budget over much of the Antarctic summer stratosphere, including in regions where strong radiative cooling due to ozone depletion can still lead to net cooling despite dynamical terms. Quantifying the contributions of changes in radiation and dynamics to stratospheric temperature trends is important for understanding how anthropogenic forcings have affected the historical trends and necessary for projecting the future.
\end{abstract}

\section{Introduction}

The pronounced polar stratospheric ozone depletion known as the Antarctic "ozone hole" has occurred each austral spring since about the mid-1980s. Smaller but substantial ozone losses are also observed in other seasons, as well as in the Arctic (Hassler et al. 2013). Since the discovery of the Antarctic ozone hole in 1985 (Farman et al. 1985), the influence of ozone depletion on stratospheric and tropospheric climate has been a

Supplemental information related to this paper is available at the Journals Online website: http://dx.doi.org/10.1175/JCLI-D-150503.s1.

Corresponding author address: Diane Ivy, Massachusetts Institute of Technology, 77 Massachusetts Ave 54-1710, Cambridge, MA 02139.

E-mail: divy@mit.edu primary focus of atmospheric science research. Ozone loss results in cooling due to decreased solar absorption and, by changing the hemispheric temperature gradient, strengthens the polar stratospheric jet. The impacts of the ozone hole are not isolated to the stratosphere. The Antarctic ozone hole has been associated with a seasonal poleward shift of the tropospheric jet and a positive trend in the southern annular mode (SAM) that has influenced Southern Hemispheric climate (Thompson and Solomon 2002; Archer and Caldeira 2008; Son et al. 2008; Thompson et al. 2011). As the ozone hole recovers, its influence on the positive trend in the SAM is expected to reverse. Yet model simulations show future projected increases in greenhouse gases will also cause a positive trend in the SAM (Thompson et al. 2011), highlighting the need to understand radiative influences on stratospheric temperature structure as a first step in understanding linkages between the stratosphere and troposphere. 
The Arctic polar stratosphere in winter and spring is much more dynamically active, and consequently warmer, than the Antarctic. While in austral spring the Antarctic lower-stratospheric temperatures are consistently cold enough for heterogeneous ozone depletion, Arctic lowerstratospheric temperatures are often near the threshold for polar stratospheric cloud formation (e.g., Solomon et al. 2014). Thus, in dynamically quiescent winters, the Arctic can also experience significantly lower ozone abundances, such as those observed in the winters of the mid- to late 1990s and 2011 (Newman et al. 1997; Manney et al. 2011), owing both to chemical depletion and weakened transport. Conversely, in dynamically active winters, Arctic ozone abundances are comparable to those of the pre-ozone depletion era. Smith and Polvani (2014) showed that ozone anomalies in the Arctic, if large enough, could influence the Northern Hemispheric extratropical spring climate in a manner similar to that observed in the Southern Hemisphere.

In a zonal mean formulation, stratospheric temperatures are controlled by radiative and dynamical heating rates (e.g., Shine 1987; Forster and Shine 1997). Radiative heating rates are determined by incoming solar radiation, aerosols, and radiatively active gases: namely, greenhouse gases, ozone, and water vapor (Shine 1987). The dynamical component is determined mainly by the dissipation of vertically propagating Rossby and gravity waves, the momentum deposition of which drives the Brewer-Dobson circulation (BDC; Holton et al. 1995). A strengthening of the BDC produces anomalous downwelling and heating in high latitudes and anomalous upwelling and cooling in the tropics. Newman et al. (2001) demonstrated a near-linear relationship between the Arctic spring lower-stratospheric temperatures and the 45-day meridional eddy heat flux at $100 \mathrm{hPa}$ averaged over $45^{\circ}-70^{\circ} \mathrm{N}$. This integrated eddy heat flux provides a measure of the planetary wave activity entering into the stratosphere. By applying this relationship, Newman et al. (2001) estimated the dynamical component of Arctic lower-stratospheric temperatures and showed that the residual temperatures were near radiative equilibrium.

A recent study by Bohlinger et al. (2014) utilized eddy heat flux data to estimate the dynamical component of Arctic lower-stratospheric temperature trends from 1980 to 2011. Further, Bohlinger et al. (2014) provided estimates of the trends driven by changes in radiatively active gases, calculated as the residual of the observed and dynamical trends. Lin et al. (2009) estimated the ozone-driven and dynamical contribution to lowerstratospheric temperature trends over the Southern Hemisphere for September and October by regressing Microwave Sounding Unit (MSU) lower-stratospheric channel 4 brightness temperatures (T4) against Total Ozone Mapping
Spectrometer/Solar Backscatter Ultraviolet (TOMS/ SBUV) total column ozone data and eddy heat flux data, respectively. A following study by Fu et al. (2010) estimated the dynamical contribution to high-latitude temperatures in both hemispheres by regressing MSU T4 against eddy heat flux data and estimated the radiative temperatures as the residual. In this study, we complement earlier studies that used eddy heat flux data to obtain dynamically driven temperature trends by directly evaluating the radiatively driven component of past Arctic and Antarctic stratospheric temperature trends (using estimated changes of historical ozone and greenhouse gases together with a radiative transfer model in a seasonally evolving fixed dynamical heating calculation). We also extend earlier work by evaluating both the Arctic and Antarctic stratospheric temperature trends and their drivers and highlight key differences between the two poles. Internal variability is also considered along with the trends. The aim of this study is to understand radiative contributions to observed polar stratospheric temperature trends, in particular how anthropogenic forcings (primarily increased well-mixed greenhouse gases and ozone depletion due to ozone-depleting substances), have likely influenced historical temperatures, a necessary element in understanding coupled climate projections of future trends.

\section{Methods}

\section{a. Data}

Historical temperature trends were estimated using monthly mean reanalysis data from the Modern-Era Retrospective Analysis for Research and Applications (MERRA; Rienecker et al. 2011). Data from MERRA are available at a resolution of $0.67^{\circ}$ longitude by $0.5^{\circ}$ latitude and include 42 vertical levels, which extend from the surface to $0.1 \mathrm{hPa}$. MERRA also provides an estimate of historical ozone abundances, constrained by partial column ozone measurements from the National Oceanic and Atmospheric Administration's SBUV, version 2 , instrument. Trends from radiosonde data were also evaluated to compare with those from MERRA. In general, the observed mid- to lower-stratospheric temperature trends are comparable to those using radiosonde station data from the Met Office Hadley Centre Atmospheric Temperature, version 2 (HadAT2; Thorne et al. 2005; Fig. S1 in the supplemental material). Trends from MERRA were also compared to the National Oceanic and Atmospheric Administration's Center for Satellite Applications and Research (STAR) Stratospheric Sounding Unit, version 2 (SSUv2; Zou et al. 2014), and MSU T4 (Zou et al. 2009) data at higher altitudes, discussed further below (see Fig. S1). 
Ozone is not well mixed throughout the atmosphere, and no continuous instrumental record exists that provides complete historical global coverage. Therefore, along with the historical ozone estimate from MERRA, three additional ozone datasets were used in this study: Stratosphere-Troposphere Processes and their Role in Climate (SPARC; Cionni et al. 2011), the Randel and $\mathrm{Wu}$ (2007) dataset (RW07), and the Bodeker et al. (2013) dataset (BDBP). These datasets are based on regression fits to vertically resolved ozone observations to provide continuous temporal and global spatial data coverage from 1979 to at least 2005. The main differences in the datasets arise from differences in the basis functions used in the regression fits to observations and the suite of observations that is included [see Hassler et al. (2013) for details]. Utilizing the three datasets provides a range of estimates of historical ozone changes to compare to MERRA's own ozone distributions, as well as one way to estimate the uncertainty. No daily climatology of the vertical profile of measured historical ozone changes is available; all three ozone datasets are zonally averaged and monthly means. For consistency, MERRA's ozone was also zonally and monthly averaged. The concentrations of well-mixed greenhouse gases, carbon dioxide $\left(\mathrm{CO}_{2}\right)$, methane $\left(\mathrm{CH}_{4}\right)$, and nitrous oxide $\left(\mathrm{N}_{2} \mathrm{O}\right)$, used in our simulations are from the SRES B1 scenario (IPCC 2001). While chlorofluorocarbons (CFCs) are also greenhouse gases, their low abundances make their relative impact on the radiatively adjusted temperatures at high latitudes negligible as compared to the included greenhouse gases (Forster and Joshi 2005).

We present the different forcing datasets used in the radiative calculations in Fig. 1. The figure shows time series of well-mixed greenhouse gases $\left(\mathrm{CO}_{2}, \mathrm{CH}_{4}\right.$, and $\mathrm{N}_{2} \mathrm{O}$ ) mixing ratios from the SRES $\mathrm{B} 1$ scenario and lower-stratospheric ozone abundances at $50 \mathrm{hPa}$ from MERRA and the three ozone databases during their peak depletion and summer months in the Arctic and Antarctic. The four different ozone time series illustrate the range of estimated values of historical ozone and its changes. Both RW07 and SPARC include by design fewer basis functions used in the regression fits and thus show less interannual variability than MERRA and BDBP (Hassler et al. 2013). Comparing the two poles, ozone exhibits larger interannual variability in spring in the Arctic than in the Antarctic. Ozone values over the last decade in the Arctic are more often similar to levels from the pre-ozone depletion era, because of dynamic variability linked to changes in wave driving. Comparing the different datasets, BDBP has significantly more ozone loss over the last two decades during the spring seasons in the polar stratosphere in both hemispheres than the other datasets. In the summer seasons, SPARC's ozone loss is negligible in both hemispheres at this pressure level, and RW07 has little ozone loss in the Antarctic, while both MERRA and BDBP show a $10 \%$ decrease over the past 30 years. As will be discussed below, use of the datasets that include summer ozone trends indicates that radiative processes strongly dominate the temperature trends in Arctic summer, making these differences a matter of particular interest in this study (Fig. S2 in the supplemental material shows additional time series of ozone from each of the datasets, further illustrating the broad range of historical ozone abundance estimates for different seasons and heights).

Long-term trends in stratospheric temperatures from the observations, radiative calculations, and the difference between the observations and radiative temperaturestermed the dynamical contribution-were estimated by least squares linear regressions on each time series. The temperature trends were estimated for two periods: 1980 2011 for direct comparison with Bohlinger et al. (2014) and 1980-2000 for the period of peak ozone depletion. For the extended period of 1980-2011, data are not available for all of the ozone datasets. The temperature trends based on datasets ending earlier than 2011 are estimated from 1980 to their given end year and are indicated in the results. Statistical uncertainties in the trend estimates are calculated from the variance of the residuals of the time series and provided at the $2 \sigma$ level, providing a $95 \%$ confidence interval. Statistical significance of the trends estimated from the time series was determined from a one-sided Student's $t$ test [as in Santer et al. (2000)] at the $95 \%$ level. As the radiatively adjusted temperatures estimated by the radiative transfer model have a nearly linear relationship with the imposed ozone forcing, the uncertainties on the radiative temperature trends largely represent the statistical uncertainty on the radiative forcing trends. Greenhouse gases are generally well mixed in the atmosphere, and their trends are fairly robust. However, ozone is not well mixed throughout the atmosphere. Therefore, the use of four different datasets of historical ozone characterizes the uncertainty in the ozone forcing. The polar cap averages are the area-weighted average from $60^{\circ}$ to $90^{\circ} \mathrm{N} / \mathrm{S}$.

\section{b. PORT model}

The radiatively adjusted temperature trends due to changes in ozone and well-mixed greenhouse gases were estimated in a seasonally evolving fixed dynamical heating calculation using the Parallel Offline Radiative Transfer (PORT) model (Conley et al. 2013). PORT is an offline model that utilizes the radiation code from the National Center for Atmospheric Research's Community Earth System Model, version 1 (CESM1), Community Atmosphere Model, version 4 (CAM4; Gent et al. 2011), 

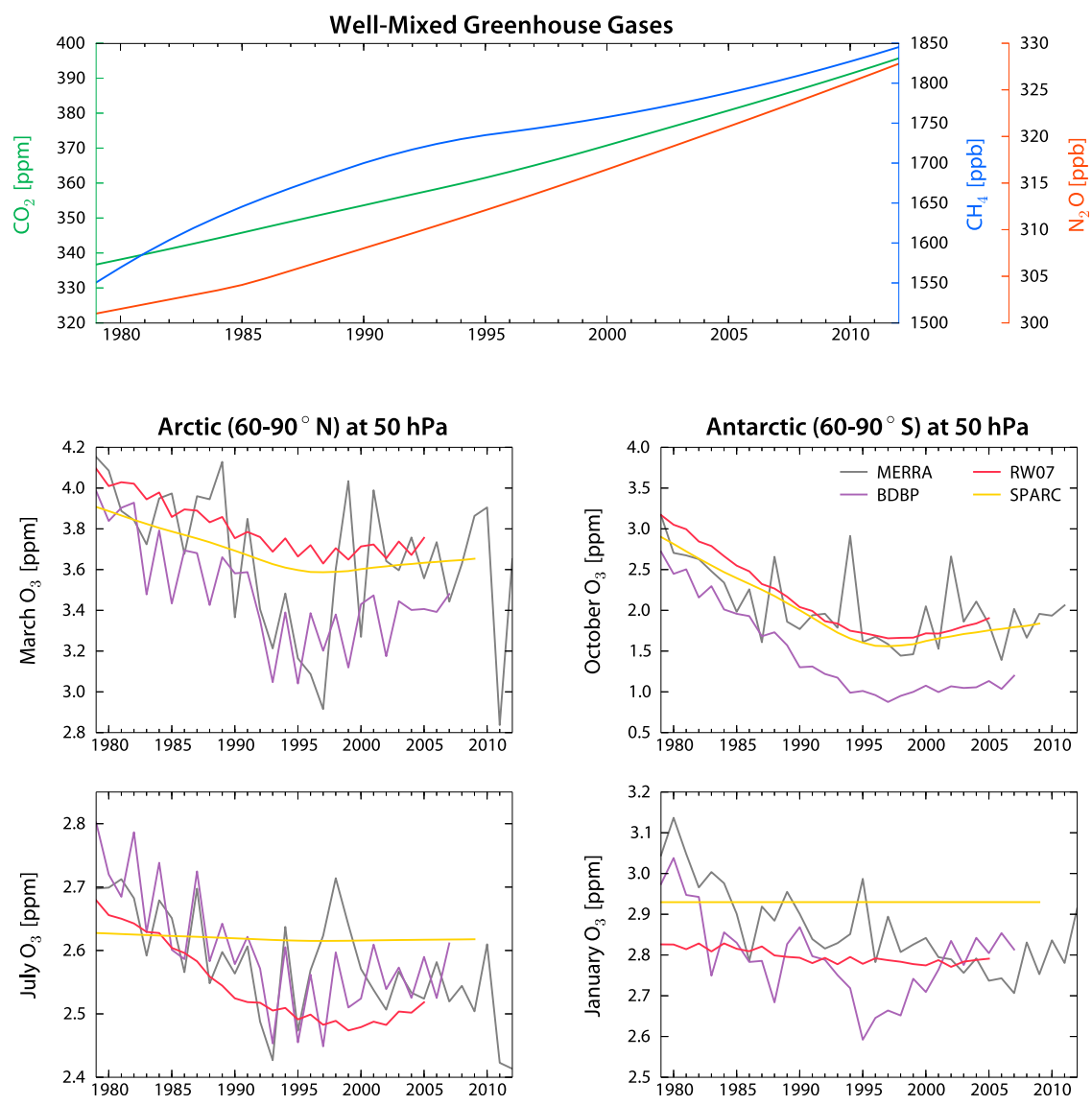

FIG. 1. (top) Time series of well-mixed greenhouse gases from the SRES B1 scenario used in the PORT simulations. Time series of polar cap-averaged ozone abundances at $50 \mathrm{hPa}$ in (middle) peak depletion months (March in the Arctic and October in the Antarctic) and (bottom) summer months (July in the Arctic and January in the Antarctic) from MERRA, BDBP, RW07, and SPARC.

and calculates temperature changes above a defined mask that is typically defined as the tropopause, but need not be. As the focus of our work is the radiatively adjusted temperatures rather than radiative forcing, the mask was lowered to $500 \mathrm{hPa}$ to allow the temperatures to adjust into the troposphere. PORT requires a baseline climatology from which to run, which was taken as the last year of a 2-yr CAM4 run with the greenhouse gases set at their 1979 abundances, while the ozone climatology was based on ozone data from BDBP averaged over 1979-83, and the prescribed sea ice and sea surface temperatures (SSTs) were from the Hadley Centre dataset climatology averaged from 1982 to 2001 (Hurrell et al. 2008). Both CAM4 and PORT were run at a horizontal resolution of $1.9^{\circ}$ latitude by $2.5^{\circ}$ longitude and with 26 vertical levels in sigma-pressure coordinates that extend from the surface up to $3.5 \mathrm{hPa}$. The radiatively adjusted temperatures were calculated by running PORT with the same baseline atmospheric state but with modified ozone and/or greenhouse gas abundances. Instead of using a fixed mean seasonal profile, as in a fixed dynamical heating calculation, PORT calculates a temperature correction using the radiative heating rates estimated from the modified radiative inputs and the seasonally evolving background climatology from the 1-yr CAM4 simulation at each time step [1.5 days, as suggested by Conley et al. (2013)], under the assumption of fixed dynamical heating. Although the ozone is prescribed as monthly means, full consideration is given to solar zenith angle changes during a given month by time stepping through the month and then averaging the result. As in CAM4, the greenhouse gas abundances are specified as well mixed globally in PORT. To test the additivity of the radiative responses, PORT was run with each of the ozone datasets and with time-varying or "fixed at 1979" greenhouse gas concentrations. To isolate the role of wellmixed greenhouse gases, an additional PORT simulation with fixed ozone abundances at 1979 levels and time-varying greenhouse gases was performed. The response of the radiatively adjusted temperatures due to changes in ozone and greenhouse gases was found to be nearly linearly additive. 

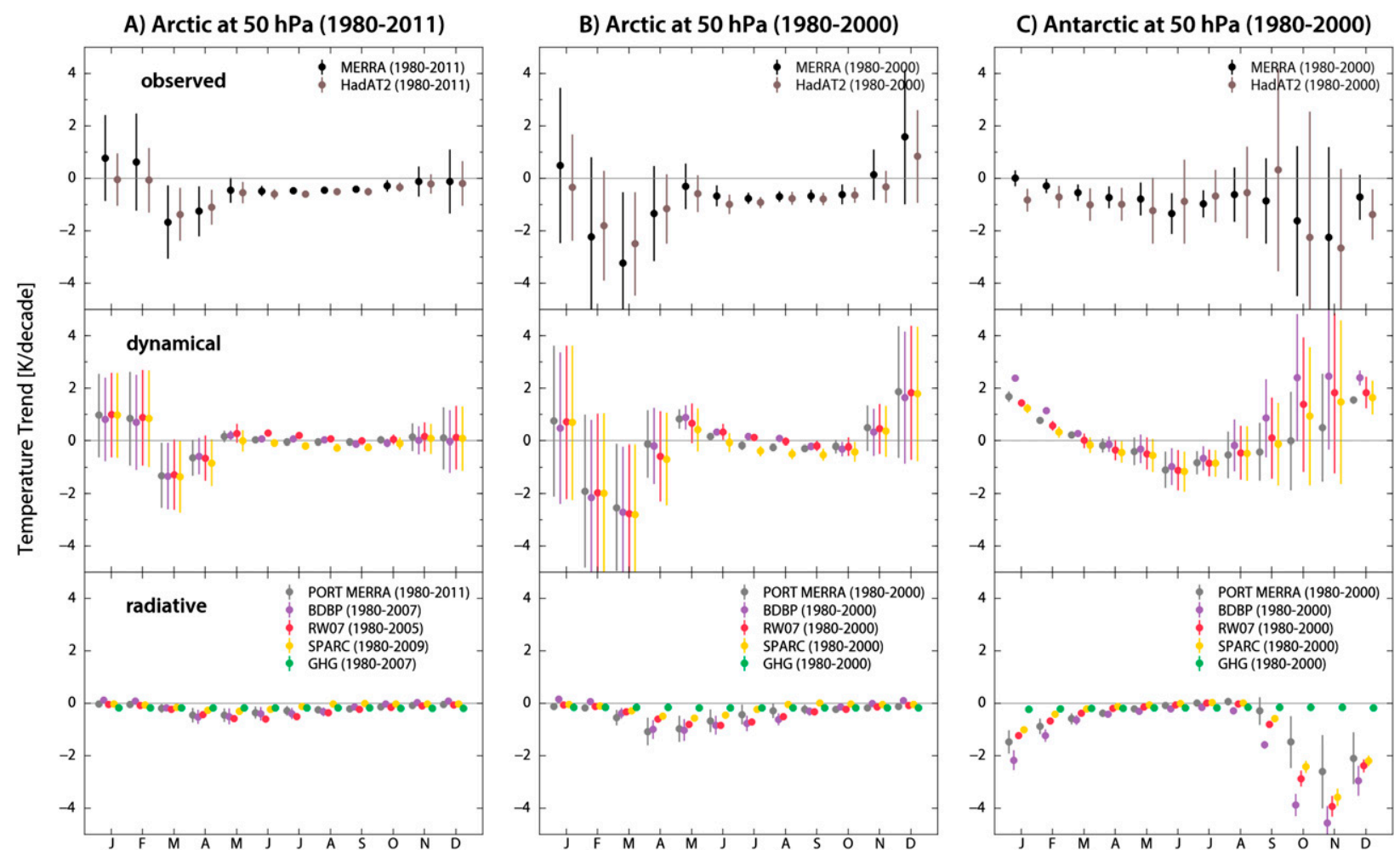

FIG. 2. Monthly temperature trends $\left(\mathrm{K} \mathrm{decade}^{-1}\right)$ at $50 \mathrm{hPa}(\mathrm{a})$ in the $\operatorname{Arctic}\left(60^{\circ}-90^{\circ} \mathrm{N}\right)$ from 1980 to 2011 , (b) in the Arctic $\left(60^{\circ}-90^{\circ} \mathrm{N}\right)$ from 1980 to 2000 , and (c) in the Antarctic $\left(60^{\circ}-90^{\circ} \mathrm{S}\right)$ from 1980 to 2000 . The temperature trends include (top) the observed trends from MERRA and HadAT2, (bottom) the radiative trends estimated from the seasonally evolving fixed dynamical heating calculation with PORT, and (middle) the dynamical contribution to the observed trends, calculated as the residual between the observed and radiative trends. The error bars represent the uncertainty on the trends at the $2 \sigma$ level.

\section{Results}

Over the past 30 years, the Arctic lower stratosphere has warmed in late winter (January and February) and cooled in all other seasons (Fig. 2a). However, the November-February trends are not significantly different than zero, while the cooling trends in MarchOctober are significant at the $95 \%$ confidence interval. The radiatively adjusted temperature trends estimated from the seasonally evolving fixed dynamical heating calculation using PORT with each of the four ozone datasets and time-varying greenhouse gases are also shown in Fig. 2a (bottom; each dataset has a different end year, which is indicated in the label and in Fig. 1). The dynamical contributions to the observed temperature trends were estimated as the residual between the observed and radiative trends (Fig. 2, middle). We can directly compare our results presented in Fig. 2a to those in Fig. 1 of Bohlinger et al. (2014), who did the opposite: they obtained the dynamical contribution to temperature trends using trends in the eddy heat flux and estimated the radiative contribution to the trends as a residual from the total observed. By construction, the observed historical trends presented here are nearly identical to those in Bohlinger et al. (2014). As seen in our study and in Bohlinger et al. (2014), the dominant component of the Arctic winter and spring trends is dynamical, and there is good overall agreement in the seasonal cycles and magnitudes of the dynamical contributions to temperature changes in the two studies. However, our estimates of the radiative cooling trends in the winter and spring are weaker, and the peak seasonality of the ozone radiative cooling occurs a month later than reported in Bohlinger et al. (2014), possibly because of the exclusion of water vapor in our analysis-a caveat we discuss later. In summer and fall, the Arctic lowerstratospheric temperature trends are predominantly driven by radiation (see also Fig. 5, described in greater detail below), consistent with the weak trend in the eddy heat flux estimated by Bohlinger et al. (2014) and Fu et al. (2010). Thus, there is broad agreement between the two approaches to estimating the radiative and dynamical contributions to Arctic temperature trends within uncertainties.

As ozone depletion peaked in the late 1990s, Figs. 2b and $2 \mathrm{c}$ and all subsequent figures show the monthly 
TABLE 1. Seasonal (DJF, MAM, JJA, and SON) and annual average temperature trends $\left(\mathrm{K} \mathrm{decade}^{-1}\right)$ for the Arctic $\left(60^{\circ}-90^{\circ} \mathrm{N}\right)$ and Antarctic $\left(60^{\circ}-90^{\circ} \mathrm{S}\right)$ from 1980 to 2000 at $50 \mathrm{hPa}$. The temperature trends include the observed trends from MERRA and HadAT2 and the radiative trends estimated from the seasonally evolving fixed dynamical heating calculation using PORT for each of the four ozone datasets and SRES B1 greenhouse gases (GHG). The uncertainties are reported at the $2 \sigma$ level; trends that are statistically significant are boldface.

\begin{tabular}{|c|c|c|c|c|c|c|c|}
\hline & & & DJF & MAM & JJA & SON & Annual \\
\hline \multirow[t]{7}{*}{ Arctic } & \multirow[t]{2}{*}{ Observed } & MERRA & $-0.23 \pm 1.88$ & $-1.62 \pm 1.16$ & $-0.70 \pm 0.24$ & $-0.37 \pm 0.36$ & $-0.73 \pm 0.57$ \\
\hline & & HadAT2 & $-0.55 \pm 1.21$ & $-1.40 \pm 0.86$ & $-0.88 \pm 0.24$ & $-0.58 \pm 0.22$ & $-0.85 \pm 0.41$ \\
\hline & \multirow[t]{5}{*}{ Radiative } & MERRA ozone & $-0.13 \pm 0.08$ & $-0.86 \pm 0.41$ & $-0.45 \pm 0.35$ & $-0.20 \pm 0.13$ & $-0.41 \pm 0.21$ \\
\hline & & BDBP ozone & $+0.12 \pm 0.05$ & $-0.79 \pm 0.32$ & $-0.73 \pm 0.28$ & $-0.14 \pm 0.11$ & $-0.39 \pm 0.16$ \\
\hline & & RW07 ozone & $-0.09 \pm 0.02$ & $-0.57 \pm 0.09$ & $-0.68 \pm 0.08$ & $-0.22 \pm 0.03$ & $-0.39 \pm 0.05$ \\
\hline & & SPARC ozone & $-0.06 \pm 0.01$ & $-0.44 \pm 0.04$ & $-0.23 \pm 0.02$ & $-0.02 \pm 0.00$ & $-0.19 \pm 0.02$ \\
\hline & & GHG & $-0.16 \pm 0.02$ & $-0.16 \pm 0.00$ & $-0.16 \pm 0.00$ & $-0.17 \pm 0.00$ & $-0.16 \pm 0.00$ \\
\hline \multirow[t]{7}{*}{ Antarctic } & \multirow[t]{2}{*}{ Observed } & MERRA & $-0.28 \pm 0.40$ & $-0.68 \pm 0.37$ & $-0.97 \pm 0.56$ & $-1.57 \pm 2.32$ & $-0.87 \pm 0.68$ \\
\hline & & HadAT2 & $-1.12 \pm 0.52$ & $-1.32 \pm 0.58$ & $-0.84 \pm 1.05$ & $-1.52 \pm 3.04$ & $-1.24 \pm 1.04$ \\
\hline & \multirow{5}{*}{ Radiative } & MERRA ozone & $-1.65 \pm 0.52$ & $-0.38 \pm 0.15$ & $+0.00 \pm 0.10$ & $-1.45 \pm 0.89$ & $-0.87 \pm 0.28$ \\
\hline & & BDBP ozone & $-2.26 \pm 0.35$ & $-0.45 \pm 0.13$ & $-0.21 \pm 0.06$ & $-3.34 \pm 0.40$ & $-1.56 \pm 0.18$ \\
\hline & & RW07 ozone & $-1.48 \pm 0.12$ & $-0.23 \pm 0.03$ & $-0.02 \pm 0.01$ & $-2.53 \pm 0.26$ & $-1.06 \pm 0.10$ \\
\hline & & SPARC ozone & $-1.25 \pm 0.08$ & $-0.13 \pm 0.01$ & $+0.02 \pm 0.00$ & $-2.19 \pm 0.20$ & $-0.89 \pm 0.07$ \\
\hline & & GHG & $-0.19 \pm 0.03$ & $-0.18 \pm 0.01$ & $-0.16 \pm 0.00$ & $-0.15 \pm 0.00$ & $-0.17 \pm 0.01$ \\
\hline
\end{tabular}

observed, radiative, and dynamical contributions to lower-stratospheric temperature trends in the Arctic and Antarctic estimated from 1980 to 2000; Table 1 presents the seasonal and annual average trends. Overall, the polar lower stratosphere has cooled in both hemispheres, with an annual mean trend of $-0.73 \pm 0.57 \mathrm{~K} \mathrm{decade}^{-1}$ in the Arctic and $-0.87 \pm$ $0.68 \mathrm{~K} \mathrm{decade}^{-1}$ in the Antarctic (Table 1). The most pronounced observed cooling is in the spring seasons, with trends of $-1.62 \pm 1.16 \mathrm{~K} \mathrm{decade}^{-1}$ in the Arctic $(\mathrm{MAM})$ and $-1.57 \pm 2.32 \mathrm{~K} \mathrm{decade}^{-1}$ in the Antarctic (SON) (Table 1). As seen in Table 1, the Arctic spring radiative cooling estimated from each of the ozone datasets is not large enough to account for the observed spring cooling trend, and dynamics contribute $37 \%-$ $63 \%$ to the observed trend, depending on the chosen ozone dataset (Table 1). Comparing Fig. 2a to Fig. 2b highlights that the observed Arctic winter trends (DJF) are not robust and sensitive to the chosen end year. The Arctic winters of the mid-1990s were characterized by weak planetary wave driving, and late winter-early spring trends ending in these years show a stronger net cooling, larger ozone loss, and a stronger radiative cooling than trends ending in 2011.

The radiative cooling trends in the lower polar stratosphere in both hemispheres are primarily due to ozone depletion (Fig. 2 and Table 1). Thus, the magnitudes of the calculated radiative trends depend on the chosen ozone dataset. The most notable difference between the datasets is the weaker estimate of radiative cooling in the Antarctic in austral spring using MERRA's ozone $\left(-1.45 \pm 0.89 \mathrm{Kdecade}^{-1}\right)$ compared to the other datasets (BDBP estimates a cooling of $-3.34 \pm$ $0.40 \mathrm{Kdecade}^{-1}$ ) and the negligible ozone cooling estimated in summer and fall in the Arctic using SPARC (Table 1). Overall, the statistical uncertainties on the radiative trends are smaller than the dynamical contribution to the observed trends, with the exception of the Arctic trends in summer and fall when the stratosphere is dynamically quiescent. The different ozone datasets, while sometimes displaying different quantitative results, give qualitatively similar results for radiative and dynamical contributions to the observed polar cap temperature trends.

Next, we explore the structure of these trends throughout the lower stratosphere and uppermost troposphere. Figure 3 shows the seasonal cycle and vertical structure of temperature trends over the Arctic from 1980 to 2000. As SPARC, RW07, and BDBP show similar ozone trends, we present for brevity only the average of these three datasets and compare these to the trends using MERRA, which has a quite different structure and is discussed further below (Fig. S3 in the supplemental material shows the results for each individual dataset). A large cooling trend appears first in the upper stratosphere in late winter and appears to propagate downward into the lowermost stratosphere in early spring. Preceding this, there is strong warming (although not statistically significant) in early winter (December-January). The radiative cooling associated with ozone depletion in the Arctic peaks in April (Fig. 3), approximately one month after the peak ozone loss, consistent with a radiative time scale of about one month in the lower stratosphere (Thompson and Solomon 2002). The spatial and temporal patterns of the radiative temperature trends due to ozone vary between MERRA and the three ozone datasets, because of the differences in the ozone structure (Fig. 3; and see Fig. S3 for the results with each ozone dataset individually). MERRA's ozone 
Arctic Temperature Trends [K/decade] (1980-2000)
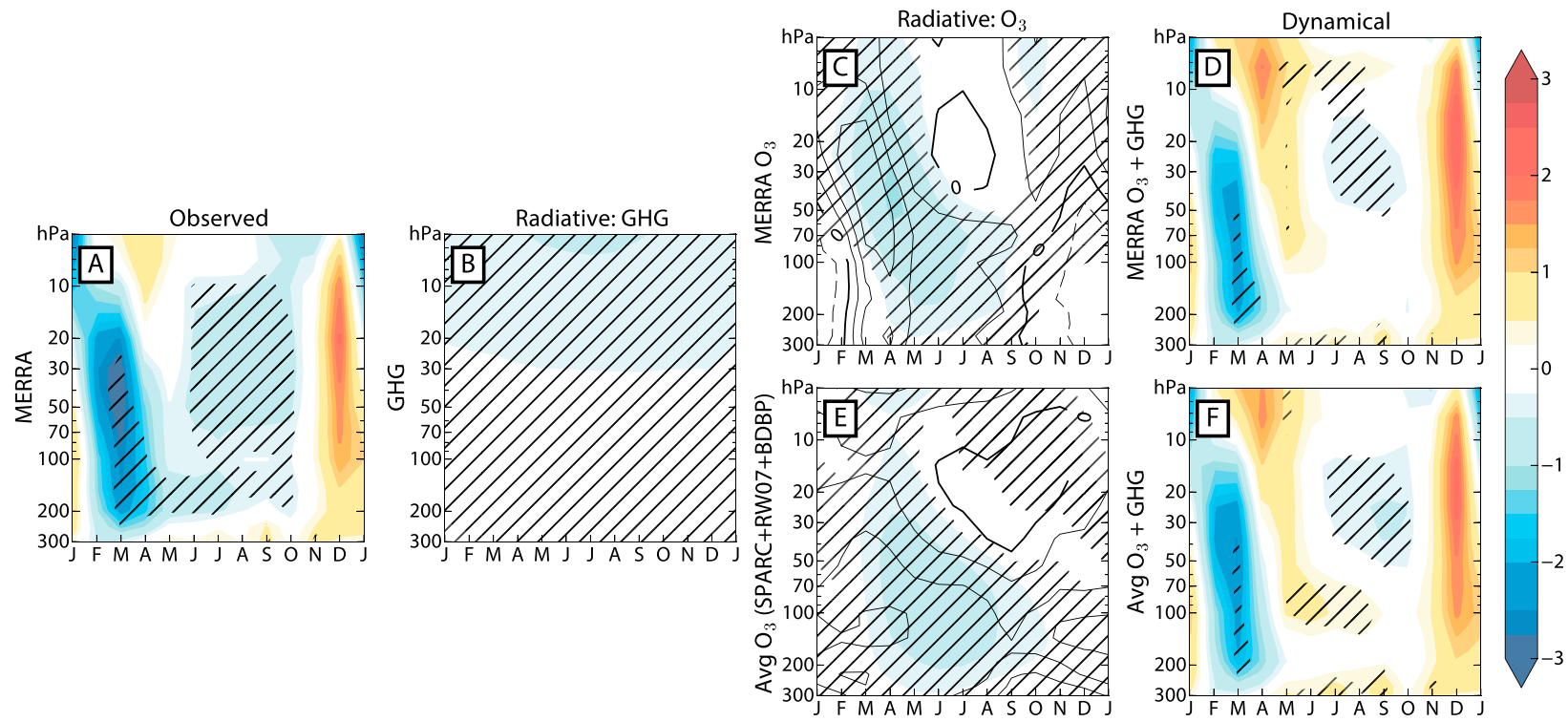

FIG. 3. Arctic $\left(60^{\circ}-90^{\circ} \mathrm{N}\right)$ temperature trends from 1980 to 2000 by month and elevation, including the (a) observed trends from MERRA and the radiative trends estimated with PORT due to (b) increasing well-mixed greenhouse gases and ozone depletion based on (c) MERRA's ozone and (e) an average of ozone depletion from BDBP, RW07, and SPARC. (d),(f) The dynamical contribution to the observed trends was estimated as the residual between the observed, historical trends and the radiative trends due to ozone depletion and well-mixed greenhouse gases. The contours on the radiative ozone temperature trend panels (c) and (e) are the ozone trends (\% decade ${ }^{-1}$; with an interval of $2.5 \%$ decade $^{-1}$; solid ozone contours are for negative values and dashed contours are for positive values). Hatching indicates trends that are statistically significant at the $95 \%$ level based on a one-sided Student's $t$ test.

trends mimic the observed temperature trends, peaking in March at $50 \mathrm{hPa}$. In comparison, the peak ozone loss in the other three datasets occurs lower (at $150 \mathrm{hPa}$ ) and is present throughout the entire winter and early spring. In summer, a significant cooling trend extends throughout the Arctic stratosphere. Both MERRA and the average of the other three datasets show ozone losses throughout the Arctic summer in the lower stratosphere $(200-50 \mathrm{hPa})$. With the exception of SPARC, which has negligible summer ozone loss, all datasets suggest that the summer ozone loss results in radiative cooling and is the dominant driver of statistically significant Arctic lower-stratospheric summer trends over the depth of this layer (see Table 1 and Fig. S3).

While the radiative cooling due to ozone loss contributes to the observed cooling in late winter-early spring, the Arctic winter and spring trends are strongly influenced by dynamics throughout the lower stratosphere (Fig. 3). The dynamical contribution to the observed trends shows warming in December and January, indicative of anomalous downwelling in the polar region and a strengthening of the BDC [as already noted in other studies (e.g., Fu et al. 2010; Young et al. 2012; Bohlinger et al. 2014; Garfinkel et al. 2015)], but it is not statistically significant. In contrast, the strong cooling associated with dynamics in February and March is indicative of a weakening of the BDC. While this strengthening and weakening of the BDC in the Arctic has been noted in previous work [e.g., by Bohlinger et al. (2014) and Fu et al. (2010)], based on trends in the lower stratosphere, Fig. 3 suggests that the temperature changes associated with changes in the BDC extend into the midstratosphere and is also seen using the MSU/SSUv2 data (Fig. S5 in the supplemental material). Furthermore, consideration of the structure of the radiative component as done here indicates that the changes in temperature associated with dynamics are not barotropic and instead display the characteristic downward propagation of circulation anomalies (see, e.g., Baldwin and Dunkerton 1999, 2001).

The most notable change in the Antarctic stratospheric climate is a pronounced spring and summertime cooling trend (Fig. 4). While the observed Arctic and Antarctic cooling trends in spring are similar in magnitude, the Antarctic cooling is confined to the lower stratosphere and predominately radiative because of the Antarctic ozone hole. Accompanying the cooling of the lower stratosphere is a strong warming trend in austral spring at $10 \mathrm{hPa}$ that has long been noted as a dynamical feature (Randel and Wu 1999). A key feature of our results is that the dynamical warming trend is not just confined to the midstratosphere. The warming extends into the lower stratosphere, is present from September 
Antarctic Temperature Trends [K/decade] (1980-2000)
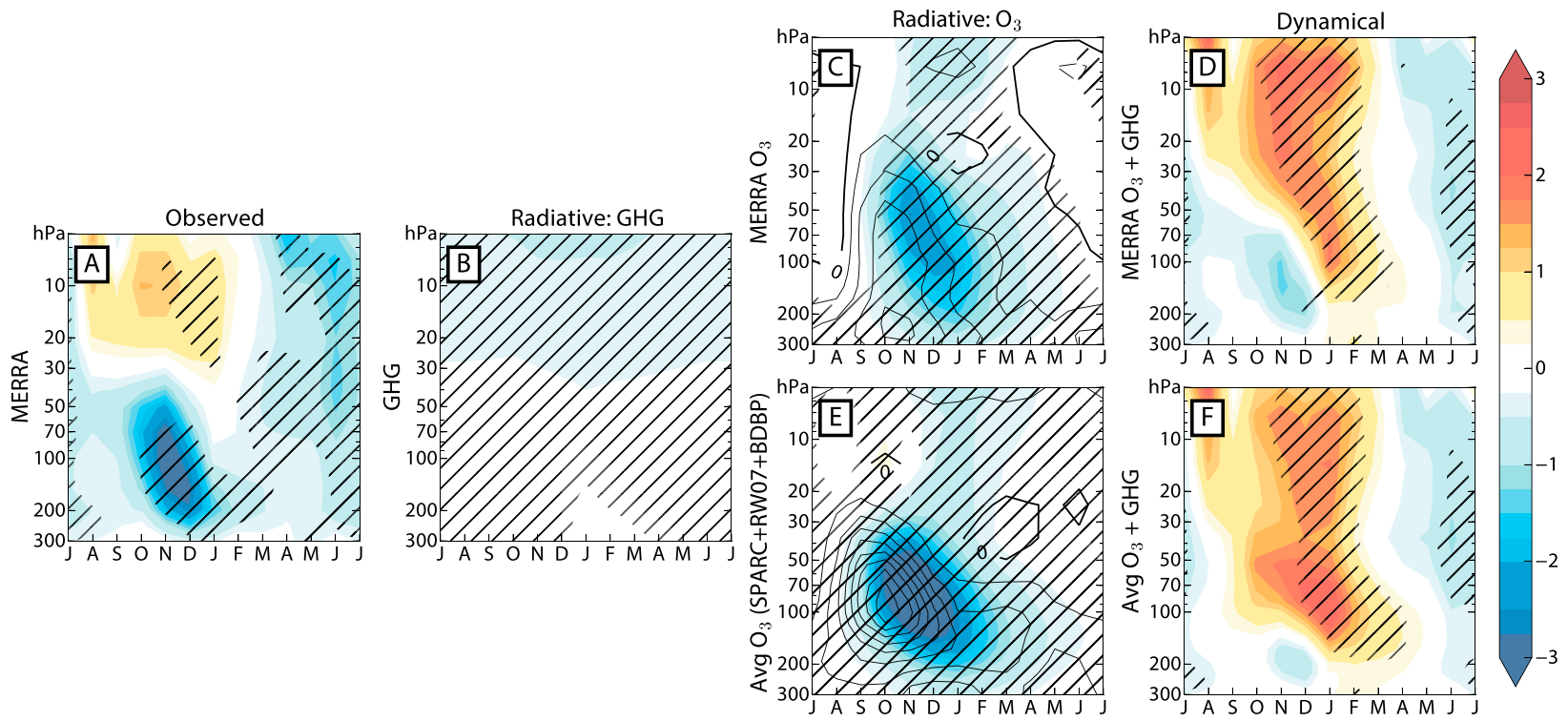

FIG. 4. As in Fig. 3, but for the Antarctic $\left(60^{\circ}-90^{\circ} \mathrm{S}\right)$. The contours on the radiative ozone temperature trend panels (c) and (e) are the ozone trends $\left(\%\right.$ decade $^{-1}$; with an interval of $5 \%$ decade $^{-1}$; solid ozone contours are for negative values and dashed contours are for positive values).

through February, and is seen in analyses with observed trends from both HadAT2 (Fig. S4 in the supplemental material) and MSU/SSUv2 (Fig. S5). Furthermore, the dynamical warming acts to weaken the radiative cooling associated with the Antarctic ozone hole by up to $55 \%$ of the total radiative cooling at $50 \mathrm{hPa}$ (Table 1) and indicates a strengthening of the BDC. Modeling studies have shown that a strengthening of the BDC is a dynamical response to the radiative cooling of the Antarctic ozone hole (Calvo et al. 2012; Young et al. 2013; Keeble et al. 2014). A similar phenomenon of dynamical warming lagging the observed cooling is suggested by the data in the Arctic but is not statistically significant throughout the depth of the lower stratosphere and is only present for a shorter period. Whether the same physical mechanism as in the Antarctic controls the Arctic warming response cannot be deduced from our radiative calculations and is left for future work.

The increase in well-mixed greenhouse gases also acts to radiatively cool the stratosphere (Figs. 3 and 4). The cooling trend increases with height as a result of increased longwave emission. Overall, the cooling trend associated with greenhouse gases exhibits a weak seasonal structure and is nearly symmetric between the two poles.

As mentioned earlier, the Arctic summer temperature trends in the lower stratosphere are largely driven by changes in radiation associated with ozone depletion. In comparison, the summer Antarctic temperature trends in the lower stratosphere show cooling due to radiation but appear to be weakened by dynamics. Figure 5
(Arctic) and Fig. 6 (Antarctic) show vertical profiles of monthly observed and radiative temperature trends in the spring, summer, and fall seasons. As noted earlier, the Arctic spring cooling trends are much larger than changes in radiation can account for and imply the role of dynamics, as seen in Fig. 5. However as seen in Fig. 2, the observed winter and spring trends are sensitive to the chosen end year. In summer and fall, the observed trends of the lower stratosphere and upper troposphere from MERRA, HadAT2, and MSU T4 lie within the range of radiative trends. Furthermore, these summer and fall trends in the lower stratosphere (down to $200 \mathrm{hPa}$ ) are mostly radiative because of ozone depletion.

In austral spring and summer, the observed Antarctic trends are generally weaker and peak at a much lower elevation (in the lower stratosphere) than the radiatively adjusted temperature trends, strongly highlighting the role of dynamics (Fig. 6). Interestingly, in January-March, the dynamical warming trend appears to cease at $200 \mathrm{hPa}$. Below this level, the observed temperature trends are within the range of the radiative cooling trends, suggesting a strong role for radiative driving in the region that links the stratosphere and Antarctic tropospheric climate.

\section{Conclusions}

In this study, we have estimated the radiative and dynamical contributions to past Arctic and Antarctic polar stratosphere temperature trends. The radiative temperature trends were based on seasonally evolving 
Arctic Temperature Trends [K/decade] (1980-2000)
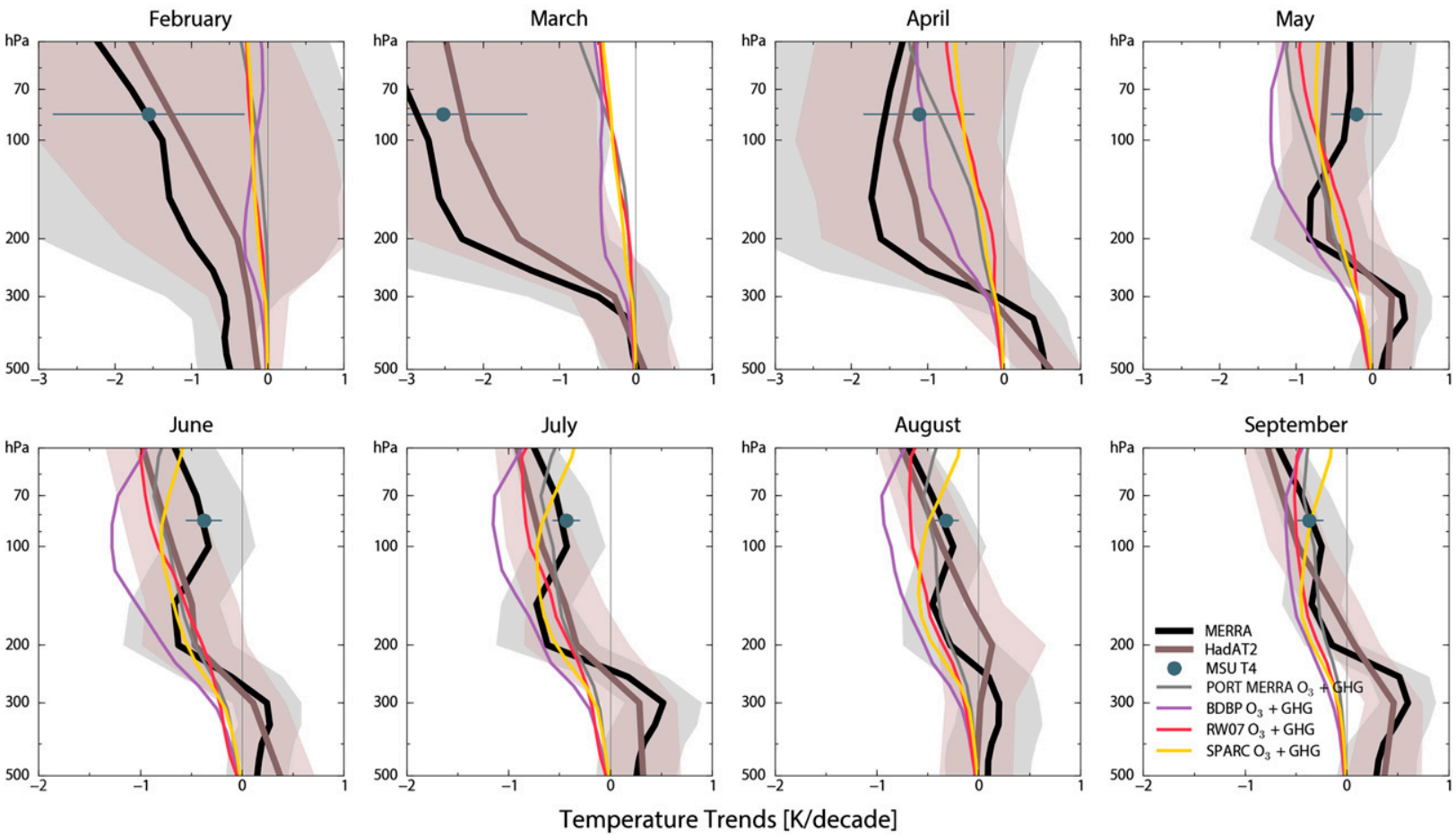

FIG. 5. Vertical profiles of monthly Arctic $\left(60^{\circ}-90^{\circ} \mathrm{N}\right)$ temperature trends $\left(\mathrm{K}\right.$ decade $\left.^{-1}\right)$ from 1980 to 2000 . The temperature trends include the observed trends from MERRA, HadAT2, and MSU T4 and the radiative trends estimated with PORT due to greenhouse gases and ozone depletion from each of the four ozone datasets. The error bars and shading on the observed trends represent the uncertainty on the trends at the $2 \sigma$ level.

fixed dynamical heating calculations using a radiative transfer model with different ozone datasets and timevarying greenhouse gas concentrations. The dynamical contributions to the observed temperature trends were estimated as the residual between the observed and radiative temperature trends. Compared to the dynamical terms, the radiative temperature trends have smaller statistical uncertainties that primarily reflect the uncertainties in the ozone trends. The use of four different ozone datasets rooted in observations provides a range on the forcing uncertainty with ozone. Last, our findings are qualitatively consistent using each of the ozone datasets (Fig. S3) and are robust to the chosen observed temperature datasets: MERRA (Figs. 3 and 4), HadAT2 (Fig. S4), and MSU/SSUv2 (Fig. S5).

Our results are comparable within uncertainties and complementary to those of Bohlinger et al. (2014), who directly estimated the dynamical contribution to Arctic polar stratospheric trends from eddy heat flux trends and calculated the radiative term as the residual. Furthermore, our study rooted in ozone observations compares well to and complements other studies that have estimated the radiative temperature trends based on model simulations (Orr et al. 2013; Keeble et al. 2014).
A caveat of the presented work is the exclusion of water vapor from the analysis. Global water vapor trends are not well characterized and therefore were not included in the radiative calculations. However, we note that the increasing trend in water vapor over the past 40 years would lead to cooling in the lower and middle stratosphere due to increased emission of infrared radiation. Forster and Shine (2002) estimated in a fixed dynamical heating calculation an annually averaged cooling trend of $0.4 \mathrm{~K} \mathrm{decade}^{-1}$ at high latitudes due to water vapor. Using a general circulation model, Maycock et al. (2014) showed that the peak cooling trend due to water vapor changes in the Arctic was in the winter seasons (December-February) and weaker in spring, summer, and fall. Hence, the radiative cooling due to water vapor trends in winter may account for the differences in the Arctic radiative trends estimated by Bohlinger et al. (2014) and this study. However, the omission of water vapor from our analysis does not affect the overall robustness of the conclusions. The observed Arctic cooling in spring is stronger than radiative trends alone could explain, even with the inclusion of water vapor, reaffirming that dynamics contributes to the spring Arctic cooling. Since the dynamical trends in the Antarctic contribute to 
Antarctic Temperature Trends [K/decade] (1980-2000)
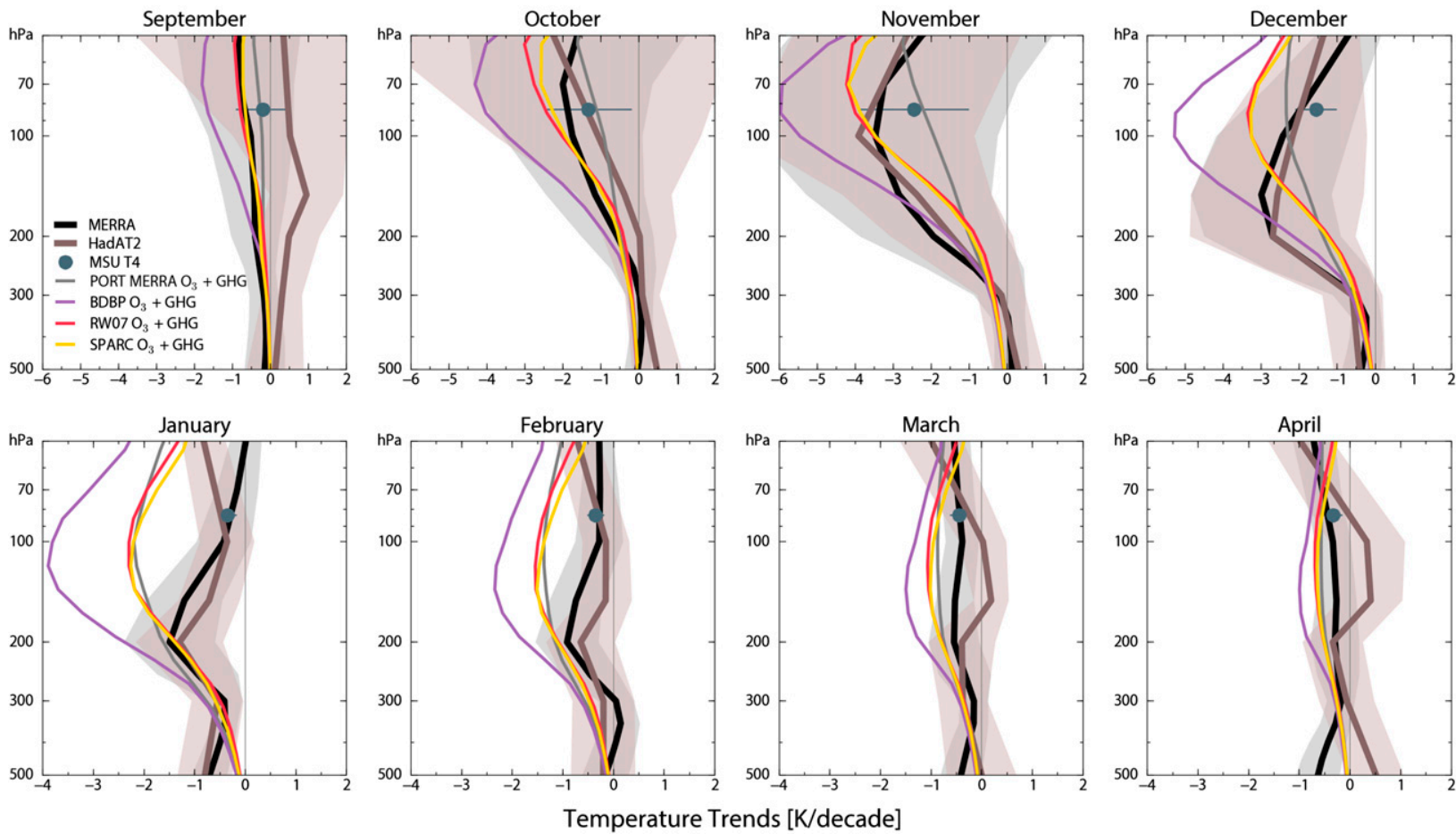

FIG. 6. As in Fig. 5, but for the Antarctic $\left(60^{\circ}-90^{\circ} \mathrm{S}\right)$.

overall warming, the inclusion of water vapor trends, which would increase the radiative cooling trends, would further strengthen the role of dynamics in the Antarctic.

In spring and summer, ozone depletion leads to substantial radiative cooling of the lower polar stratosphere in both hemispheres. Increasing well-mixed greenhouse gases lead to radiative cooling in the stratosphere that increases with height and persists throughout the year. In the Arctic, dynamics strongly influence early winter and spring temperatures, but its contribution is not statistically significant in winter. Furthermore, the Arctic winter and spring trends are sensitive to the chosen end year and likely associated with low-frequency internal variability. Garfinkel et al. (2015) used a chemistry-climate model (CCM) forced with observed SSTs and found that almost half of the Arctic stratospheric late winter and early spring cooling from 1980 to 2011 could be attributed to trends in SSTs. Furthermore, their CCM simulations showed that the Arctic cooling from 1980 to 2000 could be predominantly attributed to dynamical changes driven by changes in SSTs (Garfinkel et al. 2015). Our results complement this finding by showing that the radiative cooling driven by any of the available datasets characterizing ozone losses in Arctic spring is too small to account for the observed cooling and that dynamics contribute $37 \%-63 \%$ (dependent on the dataset) to the observed springtime cooling trend.

In late spring through fall, the Arctic lower stratosphere has cooled significantly over the past 30 years, and this result is robust to the choice of end date. Our results suggest that this cooling is almost entirely radiative, as also noted by $\mathrm{Fu}$ et al. (2010) and Bohlinger et al. (2014). Over a broad range of altitudes, radiative cooling consistent with the observed cooling is found using any of the ozone datasets, allowing us to attribute the Arctic summer and fall cooling primarily to ozone depletion. Thus, as the concentrations of ozone-depleting substances decline as a consequence of the Montreal Protocol and ozone recovers, the Arctic summer and fall cooling should weaken in the future.

In the Antarctic, ozone depletion leads to strong radiative cooling of the lower stratosphere in austral spring, summer, and fall. However unlike in the quiescent Arctic summer, the radiative cooling is weakened by a strong dynamical warming trend from late winter through early summer (September-February) and indicative of a strengthening of the BDC. Keeble et al. (2014) reported on a strong dynamical warming trend in September-February that extended throughout the stratosphere in CCM simulations using model-calculated ozone distributions. The dynamical heating in these CCM 
simulations was attributed to increased downwelling in late spring and early summer. The increased downwelling was a result of the cooling associated with heterogeneous ozone depletion altering wave propagation in the stratosphere (Manzini et al. 2003; McLandress et al. 2010; Calvo et al. 2012; Keeble et al. 2014). Fu et al. (2010) also found a strengthening of the BDC Southern Hemisphere (SH) cell in June-November in their analysis of the MSU $\mathrm{T} 4$ trends averaged over $40^{\circ}-90^{\circ} \mathrm{S}$. Our results show a later seasonality in the strengthening of the BDC. Yet both studies agree on the overall BDC strengthening in austral spring, when the dynamical warming is largest. Figure S6 in the supplemental material shows the polar cap-averaged trends in the Arctic and Antarctic from 1980 to 2005 for comparison to the timeframes used in these other studies. The dynamical trends from 1980 to 2005 show an earlier dynamical warming, more consistent with results from Fu et al. (2010), which focused on 1980-2008. Thus, the differences in the earlier seasonal strengthening of the BDC found by Fu et al. (2010) may be attributable to the inclusion of 2002, the only year with a major sudden stratospheric warming in the Southern Hemisphere. Our observation-based results strengthen the understanding that Antarctic cooling is not only controlled by radiatively driven ozone loss. While net cooling characterizes the Antarctic region from about 200 to $50 \mathrm{hPa}$ throughout November-December, over this broad layer there is a substantial compensation between dynamical warming and radiative cooling due to ozone losses. We have shown that this compensation occurs irrespective of the choice among available ozone datasets, since any one of these yields cooling that substantially exceeds the observed cooling trends in this region (see Fig. 6) over a surprisingly deep vertical extent. In contrast to the Arctic, the derived Antarctic dynamical warming trend is statistically significant and not very sensitive to the end date.

In closing, we note that our findings are relevant for studies that seek to examine the coupling of the stratospheric-to-tropospheric thermal structure and climate [see, e.g., Thompson et al. (2011), references therein, and Gerber et al. (2012)]. Grise et al. (2009) suggested that a substantial portion of the observed Antarctic upper-tropospheric temperature trends could be attributed to reduced downwelling of longwave radiation associated with the Antarctic ozone hole, with potential implications for strengthening the vortex and shifting the tropospheric jet. Here we have shown that a significant portion of the radiative cooling due to the Antarctic ozone hole has been offset by dynamical heating in the lower stratosphere, implying significant weakening of the Antarctic lower-stratospheric polar vortex. The Arctic lower stratosphere has cooled because of dynamical processes in spring, most likely associated with low-frequency internal variability, and to ozone loss in summer and fall. Further studies are needed to evaluate the extent to which models simulate these changes and determine their implications for stratospheric/tropospheric coupling and possible influence on tropospheric climate.

Acknowledgments. The authors thank Andrew Conley for his help with PORT. We also thank three anonymous reviewers for their helpful comments and suggestions, which improved this manuscript. This research was supported by NSF Grant 1419667 to MIT.

\section{REFERENCES}

Archer, C. L., and K. Caldeira, 2008: Historical trends in the jet streams. Geophys. Res. Lett., 35, L08803, doi:10.1029/ 2008 GL033614.

Baldwin, M. P., and T. J. Dunkerton, 1999: Propagation of the Arctic Oscillation from the stratosphere to the troposphere. J. Geophys. Res., 104, 30 937-30 946, doi:10.1029/1999JD900445.

—, and - 2001: Stratospheric harbingers of anomalous weather regimes. Science, 294, 581-584, doi:10.1126/science.1063315.

Bodeker, G. E., B. Hassler, P. J. Young, and R. W. Portmann, 2013: A vertically resolved, global, gap-free ozone database for assessing or constraining global climate model simulations. Earth Syst. Sci. Data, 5, 31-43, doi:10.5194/essd-5-31-2013.

Bohlinger, P., B.-M. Sinnhuber, R. Ruhnke, and O. Kirner, 2014: Radiative and dynamical contributions to past and future Arctic stratospheric temperature trends. Atmos. Chem. Phys., 14, 1679-1688, doi:10.5194/acp-14-1679-2014.

Calvo, N., R. R. Garcia, D. R. Marsh, M. J. Mills, D. E. Kinnison, and P. J. Young, 2012: Reconciling modeled and observed temperature trends over Antarctica. Geophys. Res. Lett., 39, L16803, doi:10.1029/2012GL052526.

Cionni, I., and Coauthors, 2011: Ozone database in support of CMIP5 simulations: Results and corresponding radiative forcing. Atmos. Chem. Phys., 11, 11267-11292, doi:10.5194/ acp-11-11267-2011.

Conley, A. J., J.-F. Lamarque, F. Vitt, W. D. Collins, and J. Kiehl, 2013: PORT, a CESM tool for the diagnosis of radiative forcing. Geosci. Model Dev., 6, 469-476, doi:10.5194/gmd-6-469-2013.

Farman, J. C., B. G. Gardiner, and J. D. Shanklin, 1985: Large losses of total ozone in Antarctica reveal seasonal $\mathrm{ClO}_{x} / \mathrm{NO}_{x}$ interaction. Nature, 315, 207-210, doi:10.1038/315207a0.

Forster, P. M. de F., and K. P. Shine, 1997: Radiative forcing and temperature trends from stratospheric ozone changes. J. Geophys. Res., 102, 10 841-10 855, doi:10.1029/96JD03510.

— and - 2002: Assessing the climate impact of trends in stratospheric water vapor. Geophys. Res. Lett., 29, 1086, doi:10.1029/2001GL013909.

- and M. Joshi, 2005: The role of halocarbons in the climate change of the troposphere and stratosphere. Climatic Change, 71, 249-266, doi:10.1007/s10584-005-5955-7.

Fu, Q., S. Solomon, and P. Lin, 2010: On the seasonal dependence of tropical lower-stratospheric temperature trends. Atmos. Chem. Phys., 10, 2643-2653, doi:10.5194/acp-10-2643-2010.

Garfinkel, C. I., M. M. Hurwitz, and L. D. Oman, 2015: Effect of recent sea surface temperature trends on the Arctic stratospheric vortex. J. Geophys. Res. Atmos., 120, 5404-5416, doi:10.1002/2015JD023284. 
Gent, P. R., and Coauthors, 2011: The Community Climate System Model version 4. J. Climate, 24, 4973-4491, doi:10.1175/ 2011JCLI4083.1.

Gerber, E. P., and Coauthors, 2012: Assessing and understanding the impact of stratospheric dynamics and variability on the Earth system. Bull. Amer. Meteor. Soc., 93, 845-859, doi:10.1175/BAMS-D-11-00145.1.

Grise, K. M., D. W. J. Thompson, and P. M. Forster, 2009: On the role of radiative processes in stratosphere-troposphere coupling. J. Climate, 22, 4154-4161, doi:10.1175/2009JCLI2756.1.

Hassler, B., P. J. Young, R. W. Portmann, G. E. Bodeker, J. S. Daniel, K. H. Rosenlof, and S. Solomon, 2013: Comparison of three vertically resolved ozone data sets: Climatology, trends and radiative forcings. Atmos. Chem. Phys., 13, 5533-5550, doi:10.5194/acp-13-5533-2013.

Holton, J. R., P. H. Haynes, M. E. McIntyre, A. R. Douglass, R. B. Rood, and L. Pfister, 1995: Stratosphere-troposphere exchange. Rev. Geophys., 33, 403-439, doi:10.1029/95RG02097.

Hurrell, J. W., J. J. Hack, D. Shea, J. M. Caron, and J. Rosinski, 2008: A new sea surface temperature and sea ice boundary dataset for the Community Atmosphere Model. J. Climate, 21, 5145-5153, doi:10.1175/2008JCLI2292.1.

IPCC, 2001: Climate Change 2001: The Scientific Basis. Cambridge University Press, $881 \mathrm{pp}$.

Keeble, J., P. Braesicke, N. L. Abraham, H. K. Roscoe, and J. A. Pyle, 2014: The impact of polar stratospheric ozone loss on Southern Hemisphere stratospheric circulation and climate. Atmos. Chem. Phys., 14, 13705-13717, doi:10.5194/ acp-14-13705-2014.

Lin, P., Q. Fu, S. Solomon, and J. M. Wallace, 2009: Temperature trend patterns in Southern Hemisphere high latitudes: Novel indicators of stratospheric change. J. Climate, 22, 6325-6341, doi:10.1175/2009JCLI2971.1.

Manney, G. L., and Coauthors, 2011: Unprecedented Arctic ozone loss in 2011. Nature, 478, 469-475, doi:10.1038/nature10556.

Manzini, E., B. Steil, C. Bruhl, M. A. Giorgetta, and K. Kruger, 2003: A new interactive chemistry-climate model: 2. Sensitivity of the middle atmosphere to ozone depletion and increase in greenhouse gases and implications for recent stratospheric cooling. J. Geophys. Res., 108, 4429, doi:10.1029/ 2002JD002977.

Maycock, A. C., M. M. Joshi, K. P. Shine, S. M. Davis, and K. H. Rosenlof, 2014: The potential impact of changes in lower stratospheric water vapour on stratospheric temperatures over the past 30 years. Quart. J. Roy. Meteor. Soc., 140, 2176-2185, doi:10.1002/qj.2287.

McLandress, C., A. I. Jonsson, D. A. Plummer, M. C. Reader, J. F. Scinocca, and T. G. Shepherd, 2010: Separating the dynamical effects of climate change and ozone depletion. Part I: Southern Hemisphere stratosphere. J. Climate, 23, 5002-5020, doi:10.1175/2010JCLI3586.1.

Newman, P. A., J. F. Gleason, R. D. McPeters, and R. S. Stolarski, 1997: Anomalously low ozone over the Arctic. Geophys. Res. Lett., 24, 2689-2692, doi:10.1029/97GL52831.

_ - E. R. Nash, and J. E. Rosenfield, 2001: What controls the temperature of the Arctic stratosphere during the spring? J. Geophys. Res., 106, 19 999-20 010, doi:10.1029/2000JD000061.

Orr, A., T. J. Bracegirdle, J. S. Hosking, W. Feng, H. K. Roscoe, and J. D. Haigh, 2013: Strong dynamical modulation of the cooling of the polar stratosphere associated with the Antarctic ozone hole. J. Climate, 26, 662-668, doi:10.1175/JCLI-D-12-00480.1.
Randel, W. J., and F. Wu, 1999: Cooling of the Arctic and Antarctic polar stratospheres due to ozone depletion. J. Climate, 12, 1467-1479, doi:10.1175/1520-0442(1999)012<1467: COTAAA $>2.0 . \mathrm{CO} ; 2$.

and - 2007: A stratospheric ozone profile data set for 1979-2005: Variability, trends, and comparisons with column ozone data. J. Geophys. Res., 112, D06313, doi:10.1029/ 2006JD007339.

Rienecker, M. M., and Coauthors, 2011: MERRA: NASA's Modern-Era Retrospective Analysis for Research and Applications. J. Climate, 24, 362-3648, doi:10.1175/ JCLI-D-11-00015.1.

Santer, B. D., T. M. L. Wigley, J. S. Boyle, D. J. Gaffen, J. J. Hnilo, D. Nychka, D. E. Parker, and K. E. Taylor, 2000: Statistical significance of trends and trend differences in layer-average atmospheric temperature time series. J. Geophys. Res., 105, 7337-7356, doi:10.1029/1999JD901105.

Shine, K. P., 1987: The middle atmosphere in the absence of dynamical heat fluxes. Quart. J. Roy. Meteor. Soc., 113, 603-633, doi:10.1002/qj.49711347610.

Smith, K. L., and L. M. Polvani, 2014: The surface impacts of Arctic stratospheric ozone anomalies. Environ. Res. Lett., 9, 074015, doi:10.1088/1748-9326/9/7/074015.

Solomon, S., J. Haskins, D. J. Ivy, and F. Min, 2014: Fundamental differences between Arctic and Antarctic ozone depletion. Proc. Natl. Acad. Sci. USA, 111, 6220-6225, doi:10.1073/ pnas.1319307111.

Son, S.-W., and Coauthors, 2008: The impact of stratospheric ozone recovery on the Southern Hemisphere westerly jet. Science, 320, 1486-1489, doi:10.1126/science.1155939.

Thompson, D. W. J., and S. Solomon, 2002: Interpretation of recent Southern Hemisphere climate change. Science, 296, 895-899, doi:10.1126/science.1069270.

— - — P. J. Kushner, M. H. England, K. M. Grise, and D. J. Karoly, 2011: Signatures of the Antarctic ozone hole in Southern Hemisphere surface climate change. Nat. Geosci., 4, 741-749, doi:10.1038/ngeo1296.

Thorne, P. W., D. E. Parker, S. F. B. Tett, P. D. Jones, M. McCarthy, H. Coleman, and P. Brohan, 2005: Revisiting radiosonde upper air temperatures from 1958 to 2002. J. Geophys. Res., 110, D18105, doi:10.1029/2004JD005753.

Young, P. J., K. H. Rosenlof, S. Solomon, S. C. Sherwood, Q. Fu, and J.-F. Lamarque, 2012: Changes in stratospheric temperatures and their implications for changes in the BrewerDobson circulation, 1979-2005. J. Climate, 25, 1759-1772, doi:10.1175/2011JCLI4048.1.

, A. H. Butler, N. Calvo, L. Haimberger, P. J. Kushner, D. R. Marsh, W. J. Randel, and K. H. Rosenlof, 2013: Agreement in late twentieth century Southern Hemisphere stratospheric temperature trends in observations and CCMVal-2, CMIP3, and CMIP5 models. J. Geophys. Res. Atmos., 118, 605-613, doi:10.1002/jgrd.50126.

Zou, C.-Z., M. Gao, and M. D. Goldberg, 2009: Error structure and atmospheric temperature trends in observations from the Microwave Sounding Unit. J. Climate, 22, 1661-1681, doi:10.1175/ 2008JCLI2233.1.

_ H. Qian, W. Wang, L. Wang, and C. Long, 2014: Recalibration and merging of SSU observations for stratospheric temperature trend studies. J. Geophys. Res. Atmos., 119, 13180-13205, doi:10.1002/2014JD021603. 